\title{
Three primary testicular tumours: Trials and tribulations of testicular preservation
}

\author{
Connor M. Forbes, ${ }^{*}$ Charles Metcalfe, MD; Nevin Murray, MD; ${ }^{\dagger}$ Peter C. Black, MD, FRCSC ${ }^{*}$
}

*Department of Urologic Sciences, University of British Columbia, Vancouver, BC; 'Department of Medical Oncology, Vancouver Cancer Centre, BC Cancer Agency, University of British Columbia, Vancouver, BC

Cite as: Can Urol Assoc J 2013;7(9-10):e630-3. http://dx.doi.org/10.5489/cuaj.1260 Published online October $9,2013$.

\section{Abstract}

Balancing recurrence risk, side effects and patient preference in the treatment of multiple metachronous testicular tumours can be challenging. We present the case of a young male patient who developed 3 different primary testicular neoplasms over an 8-year period, each associated with retroperitoneal lymphadenopathy requiring chemotherapy. The first tumour at age 19 was managed with radical orchiectomy. Four years later, a partial orchiectomy was performed to remove 2 small lesions. Another 4 years later, a complete orchiectomy was required for an additional tumour. This case highlights the caveats of testis-sparing surgery for testis cancer and the need for careful surveillance in these patients.

\section{Introduction}

Testicular cancer is the most prevalent neoplasm in Canadian males aged 20 to 39 , affecting on average 48.3 per 100 000, and has shown an increase in incidence over the past 40 years. ${ }^{1-3}$ Secondary malignant neoplasms occur at an increased rate in testicular cancer survivors, and multiple recurrences are also possible. ${ }^{4}$ Patients who develop multiple temporally separated testicular masses present a unique dilemma in the selection of treatment modalities. The case described here demonstrates that the risks and benefits of partial orchiectomy must be carefully weighed, and it stresses the importance of appropriate patient selection.

\section{Case report}

A 19-year-old male with bipolar disorder presented with a right testicular mass. He had undergone left orchiopexy for a cryptorchid testis at age 4 and had an atrophic left testis. An ultrasound confirmed a heterogeneous 3-cm mass occupying most of the normally descended right testis. The serum alpha fetoprotein $(58 \mu \mathrm{g} / \mathrm{L})$ and $\mathrm{B}-\mathrm{HCG}$ (human chorionic gonadotropin) (41.9 IU/L) levels were elevated and the lactate dehydrogenase (LDH) was within the normal range. Right inguinal orchiectomy was performed without complications. Pathologic evaluation revealed mixed histology, including elements of embryonal carcinoma $(40 \%)$, yolk sac tumour $(25 \%)$, immature teratoma (25\%), and mature teratoma $(10 \%)$. The tumour was organ-confined and there was no evidence of vascular or capsular invasion. Post-operatively, the tumour markers normalized and computed tomography (CT) studies of the chest and abdomen were negative for metastasis. The patient was diagnosed with stage I (T1 NOM0) nonseminomatous germ cell tumour (NSGCT).

The patient entered a surveillance program and was found 7 months later to have a rising B-HCG (from $<0.5 \mathrm{IU} / \mathrm{L}$ up to $3.3 \mathrm{IU} / \mathrm{L}$ ) associated with retroperitoneal lymphadenopathy on the right side. Three cycles of bleomycin, etoposide and cisplatin (BEP) were administered. The markers normalized, but a right-sided retroperitoneal lymph node dissection (RPLND) was performed for a residual mass. The RPLND included the para- and retrocaval lymph nodes, as well as the interaortocaval lymph nodes. Pathologic evaluation revealed mature teratoma without residual carcinoma. A summary of each occurrence of testicular cancer in this patient can be found in Table 1.

The patient presented 4 years later with lower back tightness and left testicular discomfort. A mass was palpated in the remaining originally cryptorchid left testis and an ultrasound showed 2 solid lesions $(1 \times 0.7 \mathrm{~cm}$ and $0.4 \times 0.4 \mathrm{~cm})$ at the lower pole with associated testicular microlithiasis. The tumour markers were normal with the exception of an elevated LDH (263 IU/L = 1.46 times the upper limit of normal [ULN]). Staging studies revealed left para-aortic lymphadenopathy (maximum diameter $1.8 \times 1.5 \mathrm{~cm}$ ) and small mesenteric lymph nodes $(1.2 \times 0.8 \mathrm{~cm})$ without visceral metastases. Although the serum testosterone, free tes- 


\begin{tabular}{|c|c|c|c|}
\hline & Primary \#1 & Primary \#2 & Primary \#3 \\
\hline Primary location & Right testis & Left testis & Left testis \\
\hline Primary size $(\mathrm{cm})$ & $3 \times 2.4$ & $\begin{array}{l}\# 1: 1.0 \times 0.7 \\
\# 2: 0.4 \times 0.4\end{array}$ & $1.6 \times 1.5$ \\
\hline Markers & $\begin{array}{c}\uparrow ß-H C G(41.9 \mathrm{IU} / \mathrm{L}) \\
\uparrow A F P(58 \mu \mathrm{g} / \mathrm{L})\end{array}$ & $\begin{array}{c}\uparrow \mathrm{LDH}(263 \mathrm{IU} / \mathrm{L}) \\
(1.5 \times \mathrm{ULN})\end{array}$ & $\begin{array}{c}\uparrow \mathrm{LDH}(578 \mathrm{IU} / \mathrm{L}) \\
(3.2 \times \mathrm{ULN})\end{array}$ \\
\hline Primary surgery & Radical orchiectomy & Partial orchiectomy & Radical orchiectomy \\
\hline Primary histology & $\begin{array}{l}\text { Embryonal/yolk sac/ } \\
\text { immature teratoma/ } \\
\text { mature teratoma }\end{array}$ & $\begin{array}{l}\text { 1. Embryonal } \\
\text { 2. Embryonal/ mature teratoma }\end{array}$ & Seminoma \\
\hline $\begin{array}{l}\text { Retro-peritoneal } \\
\text { disease }\end{array}$ & $\begin{array}{l}7 \text { months after surgery: mass at level } \\
\text { of left renal vein } \\
(2.0 \times 3.0 \mathrm{~cm})\end{array}$ & $\begin{array}{c}\text { On presentation: } \\
\text { para-aortic mass }(1.8 \times 1.5 \mathrm{~cm}) \text { and } \\
\text { mesenteric mass }(1.2 \times 0.8 \mathrm{~cm})\end{array}$ & $\begin{array}{l}4 \text { months after surgery: } \\
\text { para-aortic mass }(1.9 \times 1.4 \mathrm{~cm}) \text { and } \\
\text { pre-aortic mass }(2.1 \times 1.6 \mathrm{~cm})\end{array}$ \\
\hline Chemotherapy & $\mathrm{BEP} \times 3$ & $E P \times 4$ & $E P \times 4$ \\
\hline $\begin{array}{l}\text { Response to } \\
\text { chemotherapy }\end{array}$ & PR (required RPLND) & CR & CR \\
\hline
\end{tabular}

tosterone, and bioavailable testosterone were all below the reference values, the patient insisted on partial orchiectomy and would not accept radical orchiectomy. A semenalysis was not performed, but the patient had banked sperm prior to chemotherapy for the initial disease.

Pathology from the partial orchiectomy showed pure embryonal carcinoma in the larger lesion and embryonal carcinoma $(40 \%)$ mixed with mature teratoma $(60 \%)$ in the smaller lesion. The margins of both tumours were free of cancer. The surrounding testicular tissue demonstrated neither intratubular germ cell neoplasia (ITGCN) nor signs of active spermatogenesis in the seminiferous tubules. The patient received 4 cycles of etoposide and cisplatin, with subsequent complete remission in the retroperitoneum. An RPLND was not performed.

The patient was non-compliant with his subsequent follow-up, although a CT scan 3 years after surgery showed no evidence of recurrence. Despite testicular preservation, he required testosterone replacement therapy. Four years after the second testicular surgery, he presented with pain in the residual left testicle; on examination, we found a palpable abnormality. This was confirmed on ultrasound to be a $1-\mathrm{cm}$ solid mass. The B-HCG and alpha-fetroprotein (AFP) were again normal, but the LDH was elevated (578 IU/L; 3.21 times the ULN). Staging studies revealed no metastasis. At this point he was agreeable to a left radical orchiectomy, which was performed without complication. The specimen contained pure seminoma.

Four months after the right orchiectomy, a surveillance CT scan showed relapse in the left retroperitoneum (maximum diameter $2.1 \mathrm{~cm}$ ). A further 4 cycles of etoposide and cisplatin (EP) were administered, since this relapse was thought to be new metastasis from the seminoma. In total, the patient received $1100 \mathrm{mg} / \mathrm{m}^{2}$ of cisplatin from 11 courses of chemotherapy. Although all 3 episodes of metastatic dis- ease were low risk, it was necessary to give 4 cycles of EP for the second and third courses because the bleomycin could not be repeated. The EP was associated with difficult hematologic and gastrointestinal toxicity. The retroperitoneal mass resolved completely and an RPLND was not performed. At last follow-up, 1 year after the third round of chemotherapy, the patient was free of detectable cancer, but had problematic peripheral neuropathy, tinnitus, and diminished hearing.

\section{Discussion}

Men who have had 1 testicular germ cell tumour (TGCT) increase their risk of developing a contralateral TGCT by 17.6 times compared to the general population, with a cumulative incidence of $1.8 \%$ to $2.8 \%$ after 20 years. ${ }^{5}$ The unusual feature of the patient reported here is the development of a third primary tumour. Of the 403 case reports indexed in MEDLINE under both the MeSH headings "testicular neoplasm" and "neoplasms, multiple primaries," none in the last 25 years included patients with 3 or more metachronous primary testicular neoplasms. One report of 3 metachronous primary testicular tumours was found using PubMed, which recounted 2 occurrences in the retroperitoneum and 1 in the testicle. ${ }^{6}$ Our case differs in that all 3 occurrences were observed in the testes, as well as in the retroperitoneum.

This patient's disease course suggests de novo tumour formation with each new primary tumour rather than true recurrence. This assumption is based in part on the length of time between tumours and on the different histologic patterns of each. Furthermore, the history of undescended testis and the finding of testicular microlithiasis carried an increased risk of new tumour formation. ${ }^{7-9}$

This case highlights several key aspects of testicularsparing surgery for germ cell tumours. First and foremost is 
the question of patient selection. This patient had several reasons not to undergo partial orchiectomy with his first metachronous recurrence. The goal of testicular preservation includes preservation of Leydig cell function and body image. ${ }^{10,11}$ The likelihood of preserving fertility is low. ${ }^{12}$ This patient had an atrophic testis after prior orchiopexy and was already hypogonadal, indicating that he was likely to require testosterone replacement regardless of the extent of surgery, and was likely already infertile. He also had multifocal disease with associated microlithiasis at the time of recurrence, indicating a higher risk of further recurrence even though there was no sign of ITGCN in the surrounding tissue at the time of partial orchiectomy. ${ }^{7-9}$

A further argument against partial orchiectomy in this patient was his history of requiring both chemotherapy and RPLND with the first occurrence of his disease. Although not a true contraindication to testicular preservation, a patient's experience with this treatment burden often drives the patient towards choosing radical orchiectomy with a metachronous primary to decrease the risk of additional systemic therapy and cumulative toxicity from cisplatin. Finally, the patient was unreliable in his prescribed surveillance, which could perhaps have been predicted by his psychiatric history, and this was another reason to avoid testicular preservation.

Overall, testis-sparing surgery should be reserved for a highly selected subset of patients with TGCTs. The ideal candidate should have either bilateral testis tumours or a tumour in a solitary testis, with sufficient endocrine function that is expected to be preserved following surgery. ${ }^{10}$ Preservation of fertility should also be considered, and it must be recognized that any adjuvant radiation is associated with it a high probability of subsequent azoospermia. ${ }^{10}$ Testis-sparing surgery is also more feasible with tumours measuring $\leq 2 \mathrm{~cm}$ in diameter and with those located at one of the poles of the testis. ${ }^{10}$ The patient must be prepared to adhere to close follow-up. It should be noted that these restrictions apply mainly to malignant TGCTs, and there may be stronger indications for an organ-sparing surgical approach in small Leydig cell tumours and non-palpable, definitively benign masses. ${ }^{13}$

In this case, the development of new retroperitoneal disease with each primary tumour was predictably on the left side, which was not dissected with the original RPLND. The subsequent management of the retroperitoneal disease posed multiple challenges. It is usual practice in British Columbia to avoid RPLND after complete response to chemotherapy, ${ }^{14}$ but there is no evidence to guide management strategy after complete response of a retroperitoneal recurrence to a second (or third) round of chemotherapy in a patient who has had prior RPLND. Furthermore, each retroperitoneal recurrence posed the risk of being a delayed recurrence of the prior retroperitoneal disease rather than new metastatic disease. Delayed recurrences are more like- ly cisplatin-resistant and are preferentially managed with primary resection, making this a crucial distinction. ${ }^{15}$ In this patient, each recurrence in the retroperitoneum was assumed to be a new primary, rather than a late recurrence because of the temporal relationship to the respective recurrent primary in the testis, the rarity of late recurrences, and the absence of elevated tumour markers, which would be expected with a late recurrence. The second recurrence was associated with an elevated LDH, but this was consistent with metastatic seminoma. This patient's response to chemotherapy suggests that each retroperitoneal recurrence was in fact new metastatic disease, just as each testicular primary grew de novo.

\section{Conclusion}

Our case highlights difficult treatment decisions in a unique patient with multiple local and nodal recurrences of testicular cancer. Patient selection is critical for the safe and effective utilization of partial orchiectomy.

Competing interests: None declared.

This paper has been peer-reviewed.

\section{References}

1. Ellison LF, Wilkins L. Cancer prevalence in the Canadian population. Health Rep 2009;20:7-19. http:// www.statcan.gc.ca/pub/82-003-x/2009001/article/10800-eng.pdf. Accessed September 24, 2013.

2. Rosen $A$, Jayram $G$, Drazer $M$, et al. Global trends in testicular cancer incidence and mortality. Eur Urol 2011;60:374-9. http://dx.doi.org/10.1016/i.eururo.2011.05.004

3. Huyghe E, Matsuda T, Thonneau P. Increasing incidence of testicular cancer worldwide: a review. J Urol 2003;170:5-11. http://dx.doi.org/10.1097/01.ju.0000053866.68623.da

4. Fung C, Fossa SD, Beard CJ, et al. Second malignant neoplasms in testicular cancer survivors. J Natt Compr Canc Netw 2012;10:545-56. http://www.jnccn.org/content/10/4/545.long

5. Schaapveld $M$, van den Belt-Dusebout AW, et al. Risk and prognostic significance of metachronous contralateral testicular germ cell tumours. Br J Cancer 2012;107:1637-43. http://dx.doi.org/10.1038/ bic.2012.448

6. Rakusić $Z$, Krpan AM, Mareković $Z$, et al. Retroperitoneal and metachronous testicular germ cell tumors with different histology and teratoma growing syndrome-a case report. Coll Antropol 2011;35:937-40. http://www.ncbi.nlm.nih.gov/pubmed/22053583

7. Mannuel HD, Mitikiri N, Khan M, et al. Testicular germ cell tumors: biology and clinical update. Curr Opin Oncol 2012;24:266-71. http://dx.doi.org/10.1097/CCO.0b013e32835167fc

8. Tan IB, Ang KK, Ching BC, et al. Testicular microlithiasis predicts concurrent testicular germ cell tumors and intratubular germ cell neoplasia of unclassified type in adults: a meta-analysis and systematic review. Cancer 2010;116:4520-32. http://dx.doi.org/10.1002/cncr.25231

9. van Casteren NJ, Looijenga LHJ, Dohle GR. Testicular microlithiasis and carcinoma in situ overview and proposed clinical guideline. Int J Androl 2009;32:279-87. http://dx.doi.org/10.1111/i.13652605.2008.00937.x

10. Zuniga A, Lawrentschuk N, Jewett MA. Organ-sparing approaches for testicular masses. Nat Rev Urol 2010;7:454-64

11. Lawrentschuk N, Zuniga A, Grabowksi AC, et al. Partial orchiectomy for presumed malignancy in patients with a solitary testis due to a prior germ cell tumor: a large North American experience. J Urol 2011;185:508-13. http://dx.doi.org/10.1016/i.juro.2010.09.072

12. Heidenreich $A$, Weissbach $L$, Höltt $W$, et al. Organ sparing surgery for malignant germ cell tumor of the testis. J Urol 2001;166:2161-5. http://dx.doi.org/10.1016/S0022-5347(05)65526-7 
13. Giannarini $G$, Dieckmann KP, Albers $P$, et al. Organ-sparing surgery for adult testicular tumours: a systematic review of the literature. Eur Urol 2010;57:780-90. http://dx.doi.org/10.1016/j.eururo.2010.01.014

14. Kollmannsberger C, Daneshmand S, So A, et al. Management of disseminated nonseminomatous germ cell tumors with risk-based chemotherapy followed by response-guided postchemotherapy surgery. J Clin Oncol 2010;28:537-42. http://dx.doi.org/10.1200/JC0.2009.23.0755

15. Koychev D, Oechsle K, Bokemeyer C, et al. Treatment of patients with relapsed and/or cisplatinrefractory metastatic germ cell tumors: an update. Int J Androl 2011;34:e266-73. http://dx.doi.org/10.1111/ j.1365-2605.2011.01145.x
Correspondence: Dr. Peter C. Black, Gordon and Leslie Diamond Health Care Centre, 6th Floor, 2775 Laurel St., Vancouver General Hospital, Vancouver, BC V5Z 1M9; pblack@mail.ubc.ca 